\title{
La pandemia, el futuro en la salud de los niños y el desarrollo de la pediatría
} The pandemic, the future of children's health, and the development of pediatrics

La pandemia causada por coronavirus tipo 2 del síndrome respiratorio agudo grave (severe acute respiratory syndrome coronavirus 2; $S A R S-C o V-2$, por sus siglas en inglés) llegó a la Argentina los primeros días de marzo de 2020 después de su efecto devastador en China y Europa, y del comienzo de su etapa más agresiva en los Estados Unidos. Toda la información que se publicaba en las revistas médicas, aunque con escasa evidencia, indicaba que los niños parecían tener una baja incidencia y, en todo caso, un impacto, habitualmente, no grave. De forma similar, los recién nacidos no se afectaban o lo hacían rara vez y de modo mínimo.

La Argentina intentó prepararse lo mejor posible: los Ministerios de Salud de cada provincia y el de la nación se pusieron de acuerdo en que era indispensable lograr un aislamiento, distanciamiento social y otras medidas que dieran tiempo a reforzar el sistema sanitario y enlentecieran la curva de crecimiento del número de casos. El cumplimiento de todas estas medidas fue, en el inicio, casi universal y, a medida que pasaron los meses, se fue relajando parcialmente, además de tener la liberación progresiva de algunas actividades por parte de las autoridades. Sin embargo, lo que fue estricto y de cumplimiento universal fue el cierre de escuelas, jardines de infantes y centros de cuidado infantil.

También hubo un enorme efecto de concientización en la población en cuanto al lavado de manos y otros aspectos de la higiene de la casa. Las imágenes de padres y niños caminando por las calles utilizando barbijos caseros y las múltiples comunicaciones personales de los intensos cuidados de higiene hogareña resultaron elocuentes.

Sin duda, para los padres de niños pequeños, en especial, aquellos que mantuvieron sus trabajos durante la pandemia, esto fue y es un desafío enorme. La concientización de muchos padres en cuanto al riesgo de enfermarse y contagiar a los adultos mayores, que son las víctimas más sensibles de esta enfermedad, fue fundamental para que, en una gran parte de ellos, se mantuvieran el aislamiento y los cuidados personales.
El encierro, la falta de juego colectivo e interacción social y la pérdida de rutinas generaron distintos efectos negativos en la población de niños, niñas y adolescentes, cuyo análisis será imprescindible para una evaluación global de la situación. Se han identificado, además, otras situaciones con implicancias importantes para su salud integral.

Parecería haber aumentado relativamente la frecuencia de accidentes domésticos, y existe la sensación de que muchos pacientes con patologías en curso llegan tarde a la consulta. ${ }^{1,2}$ Además, se ha detectado un porcentaje importante de retraso en las inmunizaciones, principalmente, durante el primer año de vida, y de las consultas pediátricas, lo cual incide de modo negativo en el acompañamiento en el crecimiento, el apoyo a la lactancia y la detección de problemas de desarrollo. ${ }^{3,4}$

En sentido opuesto, cabe señalar la marcada disminución de la frecuencia de infecciones respiratorias. De hecho, la internación por bronquiolitis en la provincia de Buenos Aires en las primeras 29 semanas de 2020 se redujo un $83 \%$ en comparación con el mismo período de 2019. En la nación, en las primeras 24 semanas, la reducción fue del $80 \%$. Cuando analizamos la detección de virus por infecciones respiratorias bajas, encontramos que, en ese mismo período, el virus sincicial respiratorio (VSR) representó el $2 \%$ de los aislamientos, mientras que, en años anteriores, superaba el $60 \% .5,6$

Esto nos lleva a varias reflexiones y preguntas. Muchos recordamos que, durante la epidemia H1N1, hubo también una disminución de la incidencia de otras enfermedades virales. ${ }^{7}$ Más aún, los que trabajamos en terapias intensivas observamos que la frecuencia de infección intrahospitalaria fue mucho menor ese año. Es probable que un factor importante para este efecto haya sido que el miedo a una enfermedad con grave riesgo para los miembros del equipo de salud hiciera que los cuidados fueran mayores y, en las unidades de cuidado intensivo, el lavado de manos, entre otros aspectos, fuera más estricto durante dicha pandemia. Es probable que esta situación se esté repitiendo durante la pandemia de coronavirus 
disease 2019 (COVID-19, por sus siglas en inglés).

Con el legado en el cuidado de la higiene y el distanciamiento que nos dejará la pandemia, ¿mantendrán las familias esas precauciones en los próximos años? ¿Se trasladará ese aprendizaje a las escuelas y centros de cuidado infantil? Irónicamente, alguien podría sugerir que, en ese caso, ¡los pediatras deberíamos tener miedo a quedarnos sin trabajo en los próximos años! $\mathrm{O}$, por el contrario, ¿el virus sincicial respiratorio reaparecerá con mayor virulencia después de un año de estar poco presente?

Las y los pediatras y el equipo de salud han experimentado cambios en el accionar diario, cualquiera sea el lugar en que se desempeñen. La dinámica cambiante de la enfermedad, la incertidumbre y los temores similares a los de la población han incrementado la tensión en el trabajo. Todo ello, sumado, en muchos casos, al exceso de trabajo por el contagio de colegas y la transformación que ha sucedido en las instituciones donde fue necesario habilitar áreas pediátricas para la atención de pacientes adultos. ${ }^{8}$

La prolongación de esta situación y la imposibilidad de contar con precisiones que permitan definir su duración, seguramente, contribuirán a aumentar el desgaste que, por lo general, puede acompañar el ejercicio de la profesión y, por ende, es otro aspecto para tener en cuenta en el presente y para el futuro. ${ }^{9}$

Ante lo ocurrido en otros países donde la pandemia llegó a su pico, antes que en nuestro país, hay otro aspecto que preocupa: a pesar de lo realizado para evitarlo, el sistema sanitario puede verse desbordado, y los pediatras, obligados a asistir a pacientes adultos. ${ }^{10} i$ Cuál sería el impacto emocional o profesional en los intensivistas pediátricos ante la alta probabilidad de que esto ocurriera y que las camas de la Unidad de Cuidados Intensivos Pediátricos sean ocupadas por adultos a los que tendríamos que atender?

Volviendo a nuestros pacientes, en el caso de los niños que tuvieron la "suerte" de tener entretenimiento electrónico, ¿lograremos despegarlos de esos aparatos cuando se los invite a retornar a la escuela y a las actividades sociales y deportivas? ¿Cómo será la escuela en el futuro, totalmente presencial, o aprovecharemos algunos aspectos positivos de la enseñanza a distancia para evitar el efecto perjudicial de las aulas sobrecargadas en algunos puntos del Área Metropolitana de Buenos Aires? ¿Qué podrán capitalizar los docentes de nuestros niños en relación con todo esto?
Para los profesionales de la salud, y, en especial, aquellos que debieron estar más aislados por pertenecer a la población de riesgo, esto fue y sigue siendo un aprendizaje con muchas aristas duras, pero otras positivas. El descubrimiento de que se pueden desarrollar ateneos de alta calidad a distancia y que convocan a muchos más participantes que los presenciales fue una sorpresa general. De igual manera, muchos de los congresos y simposios se convirtieron en actividades virtuales que fueron masivas, bajaron totalmente los costos y mantuvieron, de todos modos, su capacidad educativa (aunque suprimieron el aspecto turístico, lo cual puede ser considerado bueno o malo según cómo se mire).

La teleconsulta ha sido muy bien aceptada en algunas especialidades, principalmente, las más técnicas, como imágenes; las que se basan mucho en resultados de laboratorio, como nefrología o hematología, pero también otras, como la psicología, la psiquiatría, etc. Para los pediatras, los especialistas que, con seguridad, estamos entre los que más apreciamos la transmisión de los afectos, el apretón de manos, la mano en el hombro de un padre o una madre y el beso a la niña o niño son aspectos que difícilmente podamos aceptar que desaparezcan. La Sociedad Argentina de Pediatría ha desarrollado una intensa actividad con llegada a todos los rincones del país en la discusión de estas problemáticas.

En este contexto de falta de certezas, los niños y sus familias nos necesitan, quizás, más que nunca. El desafío es analizar estos cambios y capitalizar esta experiencia para tener una visión amplia, junto con los distintos especialistas, que nos permita, en el futuro, ser todavía mejores y poder responder adecuadamente a esas demandas.

Dr. Néstor E. Vain nestorvain@gmail.com Servicios de Pediatría y Neonatología, Sanatorios de la Trinidad Palermo, San Isidro y Ramos Mejía Dr. Gustavo R. Cardigni gcardigni20@gmail.com

Servicio de Pediatría, Sanatorio de la Trinidad Palermo Dr. Daniel R. Capra dcapra@hotmail.com Servicio de Pediatría, Sanatorio de la Trinidad Ramos Mejía Unidad de Terapia Intensiva Pediátrica, Hospital Nacional Prof. Alejandro Posadas Buenos Aires, Argentina. 
http: / / dx.doi.org/10.5546/ aap.2020.378

Texto completo en inglés:

http:/ / dx.doi.org/10.5546/ aap.2020.eng.378

Cómo citar: Vain NE, Cardigni GR, Capra DR. La pandemia, el futuro en la salud de los niños y el desarrollo de la pediatría. Arch Argent Pediatr 2020;118(6):378-380.

\section{REFERENCIAS}

1. Bressan S, Gallo E, Tirelli F, Gregori D, et al. Lockdown: more domestic accidents than COVID-19 in children. Arch Dis Child. [Publicado en línea antes de imprimir, 2 de junio de 2020] 2020;archdischild-2020-319547.

2. French Natonal Academy of Medicine. CoViD-19, containment and accidents in children's domestic life. Bull Acad Natl Med. [Publicado en línea antes de imprimir, 15 de mayo de 2020]. 2020;10.1016/j.banm.2020.05.016.

3. Tuñón I, Sánchez ME. Las infancias en tiempos de cuarentena. Observatorio de la Deuda Social Argentina UCA. Mayo 2020. [Acceso: 5 deagosto de 2020]. Disponible en: https:/ / bit.ly/2YmWSSY.

4. Sociedad Argentina de Pediatría. Encuentros virtuales 2020. El desafío de vacunar en pandemia. 2 de Julio de 2020. [Acceso: 5 de agosto de 2020]. Disponible en: https: / / www.sap.org.ar/publicaciones / contenidos-extras / 26 / encuentros-virtuales-covid-2020.html.

5. Argentina. Dirección de Epidemiología, prevención y promoción de la Salud. Ministerio de salud. Boletín epidemiológico semana 30 de 2020. [Acceso: 5 de agosto de 2020]. Disponible en: http:/ / www.ms.gba.gov.ar/sitios / media / files / 2020/07/Bolet\%C3\%ADn-EPI-30.pdf.

6. Argentina. Dirección Nacional de Epidemiología e Información Estratégica. Ministerio de Salud. Boletín Integrado de Vigilancia, semana 26 de 2020. [Acceso: 5 de agosto de 2020]. Disponible en: https:/ / www.argentina. gob.ar/sites/default/ files/biv 502 se 26 15-7.pdf.

7. Yang L, Chan KH, Suen LK, Chan KP, et al. Impact of the 2009 H1N1 Pandemic on Age-Specific Epidemic Curves of Other Respiratory Viruses: A Comparison of Pre-Pandemic, Pandemic and Post-Pandemic periods in a subtropical city. PLoS One. 2015; 10(4):e0125447.

8. Yager PH, Whalen KA, Cummings BM. Repurposing a Pediatric ICU for Adults. N Engl J Med. 2020; 382(22):e80.

9. MatsuoT, KobayashiD, Taki F, Sakamoto F, etal.Prevalence of Health Care Worker Burnout During the Coronavirus Disease 2019 (COVID-19) Pandemic in Japan. JAMA Netw Open. 2020; 3(8):e2017271.

10. Christian M, Kissoon N. Caring for Critically Ill Adults in PICUs Is not "Child's Play". Pediatr Crit Care Med. 2020; 21(7):679-81. 